\title{
EL PROCÉS DE SEDENTARITZACIÓ DELS MERCADERS BARCELONINS AL SEGLE XV \\ LA DELEGACIÓ DE LA FEINA COMERCIAL I ELS PERILLS DE LA NAVEGACIÓ
}

\author{
JaUme Aurell I CaRdona \\ Universitat de Barcelona
}

\begin{abstract}
SUMARI
1. El mercader sedentari i el mercader rodamon.- 2. De l'execució immediata a la delegació de la gestió comercial.- 3. La incertesa dels viatges comercials $\mathrm{i}$ els perills de la navegació. 4. Conclusions.
\end{abstract}

Els mercaders barcelonins van tenir un protagonisme indubtable dins del procés d'expansió de la Corona d'Aragó durant els segles baixmedievals. Les diferents fases per que travessà aquesta expansio vingueren determinades, en gran mesura, per l'evolució interna del grup social dels mercaders. La seva identitat com a col.lectiu venia condicionada per la simbiosi que, en la figura del mercader, es donava entre grup social i grup professional.

Els mercaders, en efecte, tenien en comú, per damunt de qualsevol altra consideracio, l'exercici d'una identica professio. Aixo els va atorgar, des del primer moment, una forta cohesió com a grup social. Ultra les consideracions de caràcter més sociologic ${ }^{1}$, sembla evident que un aprofundi

'Per a aquests aspectes més socioldgics remetem a Jaume AURELL i Joan Pau RUBIÉs, Els mercaders catalans i la cultura, de l'edat initjana al renaixement, "Anuario de Estudios Medievales", 23 (1993), pp. 221-255.

"Anuario de Estudios Medievales", 24 (1994) 
ment en la concepció de la feina comercial per part dels mercaders ajudarà a fer-se una idea més reeixida del seu paper en l'evolució de la Catalunya baixmedieval.

En aquest sentit, intentarem detallar un dels trets més caracteristics de la vida professional del mercader del final de l'edat mitja: el procés de sedentarització del comerciant, a través sobretot del recurs a la delegació dels afers comercials. Aquesta tendencia pressuposa una nova concepcio de la feina mercantil, en la qual el mercader feia compatible un major grau d'estabilitat amb una gran capacitat d'adaptacio a altres cultures. Un dels factors que contribuïren més decisivament a aquesta tendència van ser una major organització de la feina comercial -que els permetia una major delegacio de responsabilitats- $\mathrm{i}$ la constatacio dels perills inherents als viatges comercials -que molts havien experimentat en carn propia o en la dels més proxims-.

A les següents planes pretenem aportar algunes de les dades més característiques referents a aquestes qüestions que sorgeixen de la mateixa consideracio del temps i l'espai professionals del mercader baixmedieval barcelonf: tenien els mercaders una vida sedentària, o més aviat es deixen portar per l'activisme dels viatges comercials? Passaven més temps a casa o a l'estranger? És certa la visio estereotipada del mercader rodamon que ens ha transmès la historiografia tradicional? Fins a quin punt els mercaders havien desenvolupat una organització que feia possible una major delegacio dels aspectes més enutjosos de la seva feina?

La documentacio notarial -testaments $\mathrm{i}$ inventaris- dóna uns testimonis molt vius $i$ eloqüents, que constitueixen les primeres respostes a aquests interrogants.

\section{El MERCADER SEDENTARI I EL MERCADER RODAMON}

En recrear la figura del mercader medieval, tendim a elaborar una imatge força estereotipada de la seva activitat. La professió mercantil consistia eminentment a viatjar, comercialitzar en el mateix lloc de l'intercanvi de les mercaderies $i$ fins $i$ tot a estar preparat per solucionar qualsevol contratemps o imprevist que se li presentés d'una manera instantània. D'aquesta manera, tot sovint s'ha atorgat als mercaders un seguit d'actituds cavalleresques, molt allunyades de la seva veritable personalitat. 
A l'extensió d'aquesta visió ha contribuït, d'una banda, el fet d'haver centrat els estudis de l'estament mercantil a través de la documentació oficial i cancelleresca i, d'altra banda, haver absolutitzat per a tots els segles medievals un tipus de mercader ideal, concordant amb la ideologia feudal ja superada als segles XIV i XV. La realitat que ens presenta la documentació notarial és ben lluny d'aquesta imatge esquemàtica.

Certament, hi ha una gran simbiosi entre el mercader $i$ el mar, entre el desenvolupament de la seva professio i la freqüencia dels viatges per la Mediterrania $^{2}$. Les operacions comercials de major volada, que tenien la dificultat addicional de la gran precarietat dels mitjans tècnics amb que comptaven, demanaven una bona dosi de fermesa $i$ atreviment per part del mercader. No devia ser tampoc aliena a aquesta realitat la denominació de mercaders aventurers que algun historiador ha constatat per als comerciants del final de l'edat mitjana ${ }^{3}$. Però aquestes situacions, més o menys aïllades, no es poden generalitzar, fent-les extensibles a la gran varietat de situacions economiques i socials tan propies del grup social dels mercaders a la Barcelona baixmedieval ${ }^{4}$.

El primer tret que es desprèn de la documentació notarial que desmenteix aquesta concepció és l'abundant presencia dels escriptoris en els inven-

\footnotetext{
${ }^{2}$ Un bon exponent d'aquesta simbiosi el trobem a l'estudi sobre el mercader de Bordeus que va dur a terme Jacques BERNARD, Navires el gens de iner a Bordeaux (vers 1440-1550), Paris, 1968. Pel que es desprèn d'aquest treball, la compenetració dels mariners i mercaders d'aquesta ciutat era força estreta, i pot ser estesa -amb les lògiques prevencions inherents a aquestes comparacions- al cas de la Barcelona baixmedieval. L'autor es refereix al mercader del segle XV com a mercator el nauta, que contrasta amb els mercaders-capitalistes dels segles posteriors. Aquest model, que cal matisar com qualsevol altra generalització, és interessant per a emmarcar degudament el tema a què ens referim en el text.

3"The epithet "merchant venturer" or "merchand adventurer" came into iuse only towards the end of the fifteenth century. But the conception of a merchant venturer, or at least of a merchant venture, goes back far beyond this" (E.M. CARUS-WILSON, Medieval Merchant Venturers, London, 1954, p. XI-XII). L'autor es refereix a la generalitat dels mercaders europeus, peró és evident que l'esmentat epítet quadra perfectament per als mercaders anglesos, que eren temuts en aquests temps per les seves activitats piratiques arreu de la Mediterrania. Referint-se al mercader del segle XVI, P. Jeannin explica que aquest "esperit d'aventura", aplicable per damunt de tot a la desenvolupada organització dels exportadors de draps anglesos, es pot aplicar a tots els homes de negocis sempre que aquesta etiqueta no es prengui amb una significació absoluta ni com un modus vivendi, sinó com una capacitat d'obrir-se al món amb un gran dinamisine (P. JEANNIN, Les marchands au XVle siecle, Paris, 1957, p. 127).

4Aquesta diversitat a què ens referim al text no és patrimoni exclusiu del mercader barceloní: vid. les reflexions respecte d'això que fa Armando SAPORI, La mercalura medievale, Florència, 1972, p. 30 i ss., a l'apartat "Grande e piccolo mercante".
} 
taris dels mercaders barcelonins baixmedievals $\mathbf{s}^{5}$,que tenen un paral.lelisme extraordinari amb els studia de la Toscana baixmedieval ${ }^{6}$. La dedicació d'un espai de la casa als estudis-escriptoris, pressuposa la necessitat de comptar amb un ambit adequat per a desenvolupar la feina organitzativa, tan característica del augment de l'augment del volum comercial d'un negoci.

Aquesta ocupació organitzativa $i$ directiva del mercader era cada cop més habitual, atenent els nous metodes comercials que s'anaven imposant ${ }^{7}$, la necessitat d'una major preparacio intel.lectual -que cada cop es feia més indispensable, atès el considerable augment de la competitivitat-, la correcta administració dels béns immobles -també cada cop més freqüents en els inventaris- $\mathrm{i}$ l'acumulació de títols $\mathrm{i}$ censals, que anaven augmentant, atesa la tendencia d'alguns mercaders per la inversió en rendes i béns no comercials ${ }^{8}$.

El procés de sedentarització del mercader barceloní no és un fet aïllat, $\mathrm{i}$ s'ha constatat ja en altres grups d'homes de negocis arreu de l'Occident baixmedieval. Aquesta tendencia a l'estabilitat i al sedentarisme professional ve relacionada amb un seguit de factors socio-economics, com Yves Renouard es va encarregar d'apuntar?: alguns descobriments tènics -els

SLa proliferació d'aquests espais a les cases dels mercaders barcelonins del final de l'edat mitjana són ben constatables a través dels inventaris. Caldria un estudi monogràfic per justificar-ne la funció, però ara només volem fer-hi referència com a testimonis fidedignes del progressiu augment de la feina organitzativa del mercader, per damunt del nomadisme comercial, tan arrelat en altres èpoques $i$ societats.

${ }^{6}$ Aquests studia han estat analitzats al capitol corresponent dins la Historia de la vida privada, coordinada per G. DUBY.

${ }^{7}$ Vid. André-É. SAYOUS, Les transformations des méthodes commerciales dans l'ltalie médiévale, "Annales d'histoire économique et sociale", 1929, pp. 161-176, que se centra sobretot en l'evolució comercial de Venècia, Gènova i Florència, com els casos més representatius. Per al cas de la Barcelona dels segles XIII-XV, vid. el recull Els mètodes comercials a la Barcelona medieval, Barcelona, 1975. Alguns treballs més detallats són: Ph. WoLfF, Une comptabilité cominerciale du XVè siècle, "Annales du Midi", LXIV (1952), pp. 131-148 i R. de ROOVER, Aux origines d'une technique intellectuelle: la formation et expansion de la comptabilité à partie double, "Annales d'Histoire économique et sociale", 1937, pp. 171-193 i 270-298.

'Una bona manera de mesurar la sedentarització del mercader baixmedieval és la comparació dels paràmetres de la mobilitat d'aquest en relació als mercaders d'èpoques anteriors: vid, p. ex., l'estudi de Stéphane LEBECQ, Marchands et navigateurs du haut moyen age. 2 Vols, Lille, 1983. En aquest sentit, Yves Renouard també és concloent: Les hommes d'affaires de la période des Croisades sont, avant tout, des voyageurs (Y. RENOUARD, Les hommes d'affaires, p. 98).

${ }^{9}$ Vid. Y. RENOUARD, Les homınes d'affaires, p. $220 \mathrm{i}$ ss. 
nous sistemes d'assegurances, els nous mètodes de comptabilitat $\mathrm{i}$ de pagament, etc.-, l'evolució social -desenvolupament urbà, exuberància demogràfica fins als estralls de la Pesta Negra, expansió de l'estament mercantil- $i$ el desenvolupament polític -amb l'entrada d'alguns mercaders en la direccio dels afers polítics, que fins aleshores sempre els havia estat vetadano van ser aliens a aquesta evolucio vers la sedentaritzacio del mercader baixmedieval.

\section{De l'execució immediata a la delegació DE LA GESTIÓ COMERCIAL}

L'increment de la tendencia del mercader baixmedieval a les tasques organitzatives-sedentdries va facilitar tot aquest procés de sedentarització. A més, aquesta prevalença del vessant més organitzatiu de la feina mercantil no anava en detriment del perfeccionament de les tècniques d'acumulació i transport de les mercaderies ni de la seva gran mobilitat: allo que anava canviant era la mateixa disposicio del mercader a l'hora d'empredre un viatge comercial.

Es precisament la millor organitzacio el que permetia al mercader, d'una banda, la possibilitat de poder delegar més la seva feina sense córrer grans riscs $i$, d'una altra banda, assolir una major rendibilitat de la seva feina comercial, els criteris racionals de la qual anirien augmentant en perjudici de la improvisacio. I és precisament aquesta major organització $i$ racionalitzacio de la feina mercantil la que li permet endegar viatges força ambiciosos, conscient que el seu negoci seguirà funcionant, bé en mans de la seva dona, bé en el cas de la delegació a qualsevol col.laborador amb la suficient competitivitat i confiança.

De l'esmentada delegació dels mercaders a gent de la seva confiança ens en parla, per exemple, l'inventari de Pere Terrassa en dos moments. En enumerar els béns enregistrats dins l'entrada del seu alberg, apunta una bota... ab un poch de vi de que beuen los missatgés ${ }^{10}$. Després, s'enregis-

\footnotetext{
${ }^{10} \mathrm{AHPB}$, Bartomeu Costa (major), Pliego de inventarios, 1455-1467, f. $210 \mathrm{v}$. El subratllat és nostre.
} 
tra una cambra hon jau lo missagé. "Aquestes anotacions presuposen l'existencia de treballadors al servei del mercader -en aquest cas, força ricque no son assimilables als esclaus, i que, sens dubte, tenen una capacitacio personal i professional molt superior a aquells. A ells se'ls devien encarregar les operacions comercials que el mercader no cregués oportú atendre directament o, si més no, feines d'una categoria inferior pero que, en qualsevol cas, demanessin un mínim de capacitacio. També es podria tractar dels aprenents que alguns mercaders tenien, que no era un fet ni de bon tros tan generalitzat com els aprenents en els obradors dels menestrals ${ }^{12}$.

Tanmateix, testaments $i$ inventaris ens han deixat una bona mostra que aquesta major delegació de la feina no afectava en cap cas la varietat geogràfica de la procedencia de les mercaderies. L'enregistrament d'una gran varietat d'objectes provinents de l'estranger a les llars dels mercaders en són una prova determinant. La procedencia d'aquestes mercaderies és consignada als documents -en els inventaris- o bé a través d'esments implícits o explícits de sortides fora del país, normalment a zones d'Ultramar -en els testaments-.

La tradició mercantívola de la Barcelona medieval venia de segles anteriors, $\mathrm{i}$ ja el segle XIII es constata una gran activitat entre els components de l'estament mercantil, que normalment es concretava amb els seus viatges comercials per la Mediterrània ${ }^{13}$. Des de molt joves, els mercaders barcelonins estaven acostumats a deixar la seva terra emprenent viatges per a perfeccionar el seu aprenentatge, per a la recerca de fortuna, per a complementar el negoci patern o desenvolupar-ne un de nou.

En aquest sentit, els mercaders barcelonins del segle XV conserven a casa seva algunes mercaderies que delaten el seu dinamisme geografic, que transcendia els límits del seu país. Trobem molts testimonis materials a les llars mercantils, a través dels inventaris. El mercader Miquel Soler tenia al seu obrador moltes peces de drap de li de Alamanya ${ }^{14}$ una peça de tela

\footnotetext{
"Id. f. $214 \mathrm{v}$.

${ }^{12}$ Alguns estudis de detall fets sobre els contractes d'aprenentatge baixmedievals per la nostra ciutat així ho han palesat (Vid. Pierre BONNASSIE, La organización del trabajo, o les planes que hi dedica Cl. CARRERE, Barcelona, un centre econòmic, I, pp. 142-149).

${ }^{13}$ Vid. les anotacions sobre els viatges dels mercaders barcelonins del segle XIII de Carme BATLLE, La vida y las actividades de los mercaderes, pp. 333-338.

${ }^{14} \mathrm{AHCB}$, Arxiu Notarial, I,4, inventari de 1419, f. $1 \mathrm{r}$.
} 
$d^{\prime}$ Erlanda ${ }^{15}$ i una copa d'argent daurada francesa ${ }^{16}$. Aixi mateix, al seu encant apareix la venda d'una copa ab peus frances, pel preu de 5 lliures $\mathrm{i}$ 1 sou $^{17}$.

Tot $\mathrm{i}$ que desconeixem la funcionalitat que aquest mercader atorgava a cadascun d'aquests objectes, el fet que a casa seva tingui mercaderies $i$ objectes de luxe provinents d'una àmplia representació geogràfica (Alemània, França, Irlanda) palesa fins a quin punt el mercader barceloni tenia una visió cosmopolita del mercat, que li feia tenir una mentalitat molt més oberta i expansiva -al segle XV- del que s'ha volgut veure en algunes interpretacions. És evident que, en aquest cas, és impossible determinar si aquestes mercaderies eren fruit dels diferents viatges d'aquest mercader 0 eren objectes heretats o comprats al mercat barceloni, pero si que il.lustren l'abast de la seva cultura geografica i comercial. Un cosmopolitisme que no li fa menysprear al més mínim els productes de la seva terra, que també comercialitza abundosament (afirma, per exemple, que té bastants drap de li de la terra $)^{18}$.

Per altra banda, a l'inventari del mercader Macià Català -confeccionat al 1445- hi ha enregistrades moltes mercaderies relacionades amb la llana: sacha de canamds en que havia lana blancha en flota d'Arag $\sigma^{19}$; saquet de canamas ple de lana blancha en flota de Malorques ${ }^{20}$; altre sacha $a b$ lana vermella d'Anglaterra ${ }^{21}$; i també alguns casos de drap de Sicnlia i de Niça ${ }^{22}$. Totes aquestes mercaderies demostren que tampoc no es tractava de mercaders amb una direccionalitat univoca del seu comerç, sinó que sabien canviar l'origen preferent de les mercaderies segons la conjuntura del moment, comptant amb diversos comerços alternatius.

Un altre exemple de caracteristiques similars el trobem a l'inventari del mercader Guillem Ferrer, de l'any 1398. Alguns dels béns personals i de

\footnotetext{
${ }^{15}$ Id., f. Ir-Iv.

${ }^{16} I d .$, f. $2 v$.

${ }^{17} I d .$, f. $5 r$.

${ }^{18}$ Id., f. Iv.

${ }^{19} \mathrm{AHCB}$, Arxiu Notarial, 1,8, inventari del 1445. f. 3v.

${ }^{20}$ Id., f. $3 v$.

${ }^{21} I d .$, f. $4 v$.

${ }^{22}$ Id., f. $3 v-4 r$.
} 
les mercaderies que s'apleguen a casa seva ens confirmen la idea d'aquest cosmopolitisme d'un bon grup dels mercaders barcelonins de l'epoca. En concret, trobem una vanova napolitana ${ }^{23}$; una vanova prima, nova, siciliana de drap de cotomina ${ }^{24}$, unes tovalles francesses (dins d'un armari) ${ }^{25}$, un cofre de Pisa, un mantell de florentl vert folrat de panxes de vays, una "cot de dona de florentr tenat, ab perfill de drap negre ab les manegues amples folrades, un manill alexandri, barrat de blau e de blanch"26; una "stora blancha e negra, de obra de Valencia, squinçada, qui està entorn paret" ${ }^{27}$, un martinet de ferre flemench, abte per a parar ballestes ${ }^{28} ; \mathrm{i}$ molts més articles de Florència, Pisa, Sićlia, Valencia i Saragossa. Ja hem esmentat la riquesa d'aquest mercader ${ }^{29}$, que explica aquest gran abast geografic de les seves pertinences, pero que no deixa de ser un bon exemple per al que anem comentant. A més, aquesta visió universal tampoc no el du -un cop més- a infravalorar els articles de la seva terra: en aquest cas també hi ha l'oportuna referencia a alguns draps de la terra ${ }^{30}$.

Els exemples d'inventaris es podrien multiplicar, pero sempre ens quedaria el dubte del veritable origen d'aquests objectes estrangers: ben mirat, la presencia a Barcelona dels mercaders genovesos, cada cop més freqüent, i d'altres comerciants europeus, devien fer molt assequible la compra d'aquestes mercaderies sense necessitat d'anar-se'n a l'estranger. Tot i aixl, el testimoni d'aquests inventaris tan internacionalitzats no és de cap manera menyspreable, perque l'origen comercial d'aquestes mercaderies devia venir determinat, si més no, per dos camins: els viatges dels mercaders barcelonins per la Mediterrània i la presencia dels mercaders estrangers.

\footnotetext{
${ }^{23}$ AHCB, Arxiu Notarial, I, 1, inventari del 1398, f. 64r.

${ }^{24}$ Id., f. 64r.

${ }^{2 s}$ Id., f. $64 \mathrm{v}$.

${ }^{26} I d .$, f. $64 \mathrm{v}-66 \mathrm{r}$.

${ }^{27}$ Id. f. $66 \mathrm{v}$.

${ }^{22}$ Id. f. $65 \mathrm{v}$.

${ }^{20}$ Vid. l'article esmentat de Josep Maria CASAS HOMS, L'heretatge d'un mercader.

${ }^{30}$ Vid., per exemple, l'inventari de l'esmentat mercader, f. 66r.
} 


\section{LA INCERTESA DELS VIATGES COMERCIALS I \\ ELS PERILLS DE LA NAVEGACIÓ}

Una de les raons que dugueren els mercaders a delegar els viatges $\mathrm{i}$ les gestions més complicades de la seva feina comercial van ser els perills inherents a la navegació d'aquell temps. Aquests perills en concretaven, bàsicament, en dos aspectes: la possibilitat del naufragi i l'augment que, al final de l'edat mitjana, havien experimentat el piratisme i el corsarisme.

El testimoni dels testaments son prou eloqüents pel que fa a aquests perills. En primer lloc, per l'expressio que sovint fan servir els mercaders per designar el punt d'arribada dels seus viatges: Ultramar. Aquest mot el trobem sovint als documents, i fa referencia a una zona -més o menys indeterminada- que podia comprendre la Mediterrània en la seva totalitat.

El mercader Francesc Despuig retorna a la seva dona els diners que aquesta ha gastat en el manteniment dels afers comercials del seu marit mentre aquest ere de viatge: "Item reconech a la dita dona na Valençб, muller mia, que ella, de béns seus propris e perafernals, ha despeses per affers e negocis meus propdits stant jo en lo viatge que darrerament he fet en les parts de Ultramar"31. A desgrat de les connotacions purament professionals que es desprenen d'aquest comentari (l'ajut de la dona en les tasques comercials, la capacitat del mercader de delegar la seva feina i la possibilitat d'embarcar-se en llargs viatges sense que hi hagi una interrupcio dels seus afers comercials), també cal parar atenció en l'adverbi darrerament que empra el mercader, fent aix $($ una possible menció implícita d'altres viatges que pot haver realitzat.

Alguns mercaders, fins $i$ tot, trobarien la seva mort en el mateix viatge sobretot pels riscs inherents al transport marítim de l'época ${ }^{32}$, que es trobava limitat en gran mesura pels mancaments tecnics $i$ pel perill que repre-

\footnotetext{
${ }^{31}$ AHPB, Amau Lledo, Manual de testainents, 1398-1404, f. 36 v (testament de Francesc Despuig, 8.VI.1404).

${ }^{32}$ Els avanços técnics més considerables van venir precisament al segle $X V$, peró no es van generalitzar a Catalunya fins després de la descoberta d'Amèrica (vid. Arcadi GARCla SSANZ, Historia de la Marina catalama, Barcelona, 1977, sobretot als primers capítols (pp. 17-118) i els que fan referència explícita al segle XV (pp. 289-314). Vid. també els comentaris de Armando SAPOR, Le Marchand lialien au Moyen Age, Paris, 1952, p. XXXVIl-XL (dins l'apartat "Voies de communication").
} 
sentava el piratisme $e^{33}$, o mentre comerciaven en altres terres de la Mediterrània. Les notícies d'aquestes defuncions devien colpir fortament els sentiments dels seus familiars.

Un exemple impressionant de com eren rebudes aquestes notícies el trobem en el testament del mercader Pere Salelles. Aquest mercader, en assabentar-se de la mort del seu gendre Antoni Luna (qui tos temps me fou obedient com a bon fill que era), torna a redactar el seu testament. Llavors, li dedica un comiat emocionat, saltant-se l'ordre i l'estructura preestablerta pels canons. La referencia es fa dins el nomenament dels marmessors, precisament perque Salelles vol fer ressaltar la seva absencia: "...fas e ordon mon testament scrit de ma propia mà, qui és ma derrera volentat, en lo qual alegesch e pos marmassors e de aquest present meu testament exequdors los honrats en Francesch Mas e en Johan Mayosa, gendres meus; de n'Antoni Luna, gendre meu, al qual prech Déu haia la sua ànima per tant com no havia molt, com no havia pus de dos jorns, que sabl que Déus lo savia pres-la (sic) en la illa de Malta per letres del damunt dit Francesch Mas, qui me n'avisà de Saragossa de Cicnia, per aquesta rahó non fas mencio de fer-lo marmassor, ans per la sabuda de la sua mort mut ara novellament aquest testament; Déus haia la sua anima, axi com aquell qui tos temps me fou obedient com a bon fill que era, axI mateix elegesch ab los damunt dits.." ${ }^{34}$.

Segons es desprèn d'aquestes paraules, la pèrdua d'un parent proxim entre les famflies dels mercaders per raó d'un viatge comercial devia ser una experiencia habitual, per bé que sempre colpidora. A més, aquest document ens transmet altres aspectes de la vida quotidiana dels mercaders que val la pena apuntar. En primer lloc, queda ben reflectida l'espontaneïtat i la naturalitat dels mercaders barcelonins a l'hora de redactar els testaments -que augmenta en els redactats en català-, que tira per terra qualsevol prejudici que es pugui tenir envers la fiabilitat de la documentació notarial. Aquesta mateixa flexibilitat és la que els permet fer aquests incisos tan espontanis i sentits. En segon lloc, el paper dels gendres a la famnlia dels mercaders i la seva funcio cohesiva en l'estament mercantil (que, en alguns casos, com el present, tenien les mateixes prerrogatives que els fills).

\footnotetext{
${ }^{33}$ Vid., per exemple, Anna UNAU, Mariners, pirates $i$ corsaris catalans a l'zpoca medieval, Barcelona, 1986.

${ }^{34}$ AHPB, Francesc Barau, Primus liber ultimarum voluntatum, 1416-1433, f. 44r (testament de Pere Salelles, 15.IV.1423).
} 
Uns altres aspectes que es desprenen de la interpretació d'aquest document són la capacitat d'una ràpida reacció davant els esdeveniments que demostren alguns mercaders -Pere Salelles només deixa transcórrer dos dies des que s'assabenta de la mort del seu gendre per refer el seu testament (com no havia pus de dos jorns)- o la immediata invocació a Déu per l'ànima dels difunts (sembla que tingui pressa per invocar Déu, quan detalla els dies que fa que sap la notícia -que sabl que Déus lo savia pres-la).

Una altra mostra de la inseguretat dels mercaders, sobretot per la manca de seguretat de la seva feina, és la indeterminació que alguns demostren en elegir diversos llocs de sepultura, segons el lloc on morin. El mercader Jofre Sirvent, per exemple, fa una cláusula en l'elecció de la sepultura ("Sepulturam vero corporis mei, casu quo decedam in civitate Barchinone, fieri volo et ordino in cimiterio fratrum minorum Barchinone") ${ }^{35}$, que constat aquesta inseguretat. Mateu Desvall afirma en el seu testament que vol que l'enterrin al monestir dels Predicadors de Barcelona si mi covindrd morir en la ciutat de Barchinona ${ }^{36}$. Francesc Asbert, per la seva banda, en fer l'eleccio de la sepultura, afirma: "Eligo autem corpori meo sepulturam si obiero in Barchinona in cimiterio Sedis Barchinone"37.

És interessant constatar aquf que aquests aclariments condicionals (si moro, si obiero...) no apareixen d'una manera sistemàtica: els devien posar els mercaders que realment tenien una inseguretat certa del lloc de la seva mort. Aixo ho demostra ben be el cas del mercader Jofre Sirvent ${ }^{38}$, el qual, al llarg de la seva llarga vida (entre la redaccio del testament $-1 . V$. 1426- i la seva obertura -12.VII.1470- hi ha 44 anys), va fer força viatges, alguns no exems de perills: de fet, va patronejar una expedició a Alexandria de Rodes que va naufragar i allà va perdre el seu germà Lluis, tal com ho consignem a continuacio.

\footnotetext{
${ }^{35}$ AHPB, Antoni BROCARD, Liber testainentoruin secundus, 1415-1445, f. 69v (testament del 1.V.1426).

${ }^{36}$ AHCB, Arxiu Notarial, III, I, testament del S.III.1378, f. Ir. En aquest cas, certarnent, la "por" a morir fora de Barcelona pot venir deterninada tant pels seus viatges comercials com per les freqüents visites que -segons es desprèn del context del testament- feia a Camprodon, lloc d'origen dels seus pares.
}

${ }^{37}$ AHPB, Pere Ullastrell, Manual de testainents, 1382-1387, f. 39r (testamerit del 23.VIII.1384).

39.Vid. n. 35. 
En l'obertura del testament del mercader Lluis Sirvent -germà de Jofre-, feta menys de dos anys després de redactar la seva última voluntat (el testament és del 1.VIII.1443 i l'obertura del 29.VII.1445), se'ns detalla aquesta dramàtica circumstancia: "Noverint universi quod die jovis intitulata XXIX mensis julii, anno a Nativitate Domini MCCCCXXXXVo, in presencia etiam Anthoni Seguer, mercatoris, Petrus Talo, sartoris civium Barchinone, Jacobi Moret, mercatoris, testium ad ista vocatorum specialis et assumptorum, fuit lectum et publicatum per me dictus notarius testamentum predicti venerabilis Ludovici Sirvent, quondam, mercatoris civis Barchinone, qui in mense octobre anni Nativitate Domini MCCCCXLIIII, veniendo de partibus Alaxandrie de Rodi cum quadam galea patrotzinata pro dictum Jaufredum Sirvent (de qui hem parlat al pardgraf anterior), fratrem suum, que naufragium passa fuiit in maribus ... dies suos clausit extremos, una cum partibus notabilibus personis in multitudine scitis copiosa pro dolor. Et predicta publicatio fuit facta dicta die in dicto hospicio in quo idem Ludovicus morabatur in dicta civitate Barchinone" ${ }^{\prime \prime 39}$.

El dramatisme d'aquesta narració ens fa ben present fins a quin punt la inseguretat dels viatges marítims devia estar present a la vida quotidiana de les famflies dels mercaders, colpides de tant en tant per successos d'aquesta naturalesa. El germà supervivent devia viure des d'aquell moment amb la memoria molt fresca d'aquell naufragi (hi fos ell personalment o no), i probablement aquests fets poden explicar el progressiu afany de sedentaritzacio que trobem en alguns mercaders.

Més endavant, ja a mitjan segle $\mathrm{XV}$, anem trobant referències als testaments sobre la incertesa de l'hora de la mort, pero no se solen repetir el mateix tipus d'expressions -és a dir, que no és una anotació maquinal sinб premeditada. El mercader Bartomeu Montbrú, per exemple, afirma l'any 1441 que vol ser enterrat als framenors casu quo me mori contingat in hac civitate Barchinone ${ }^{40}$. I, també als anys quaranta, el mercader Pere Vendrell deixa previst l'enterrament per si mor a Barcelona o per si mor a Girona $^{41}$, fórmula aquesta que també fan servir altres mercaders -normalment sempre en el marc de les altres ciutats catalanes, bé per raons fami-

\footnotetext{
${ }^{39} \mathrm{AHPB}$, Id., f. 63v (testament del 1.VIII.1443).

${ }^{40} \mathrm{AHPB}$, Jaume Mannany, Liber prionus testamentoruin, 1420-1461, f. 26v (testament del 21.VI.1441).

"AHPB, Antoni Joan, Primus liber testamentorum, 1447-1489, f. 140V (testament del 24.II.1449).
} 
liars, bé per raons comercials. L'any 1437, el mercader Joan Gras també dubta de que hagi de morir a Barcelona, $\mathrm{i}$ demana ser enterrat al monestir de San Agusti, on el seu pare va ser inhumat, només en el cas que mori a Barcelona ${ }^{42}$.

Alguns mercaders van encertar-ho quan consignaven al testament els seus dubtes sobre el lloc on els tocaria morir. Pere Bernat va testar, completament sa, el 9 de juny de 1448, demanant ser enterrat a Santa Maria del Mar si moria a Barcelona ${ }^{43}$. Els seus temors van ser confirmats només sis mesos després, atès que a l'obertura del testament, el 22 de desembre der mateix any, s'enregistra la seva mort, succeïda en terres sicilianes ${ }^{44}$. És un testimoni realment impressionant, molt viu i eloqüent respecte al que anem apuntant.

Aquests exemples d'indeterminació del lloc de la mort connecten també amb les raons que portaven els mercaders a testar quan encara estaven sans, normalment motivats per la inseguritat $i$ incertesa del moment de l'hora de la mort (tal com molts ho diuen explícitament a les invocacions: "res més cert que la mort i res més incert que la hora de la mort)".

Alguns d'ells testaven, trobant-se encara sans, en el moment d'iniciar un viatge comercial, com devia ser el cas de l'esmentat Pere Bernat. Tanmateix, alguns reconeixen expliçitament al començament del testament aquesta motivacio, que feia augmentar encara més la incertesa respecte a l'hora de la seva mort. Miquel Batlle, mercader gironf totalment establert a Barcelona -com ho delata el nomenament dels marmessors i dels testimonis, tots ells ciutadans de Barcelona- afirma estar sanus per Dei gratiam mente et corpore, per aclarir immediatament el perque del seu testament: "quia de proxima viagium facere debeo, Deo volente, cum navi venerabilis Francisci Spital, ville Sancti Felicis Guixellenti (Sant Feliu de Guixols) versus partes de Lavant, timens imminens periculum navis,..."45. Aquest comentari també és força expressiu de l'objectivitat dels riscs inherents a la professio mercantil. Miquel Batlle, de fet, va morir només quatre anys després de

${ }^{42}$ AHPB, Bemat PI, Secundus liber testainentoruin, 1417-1440, f. 153r (testament del 11.VII.1437).

${ }^{43} \mathrm{AHPB}$, Bemat $\mathrm{Pi}$, Tercius liber testainentoruin, 1418-1450, f. 137v (testament del 9.VI.1448).

${ }^{4} I d .$, f. 139r.

${ }^{45}$ AHPB, Esteve Mir, Manual de testainents, 1442-1457, f. 34r (testament del 16.V.1450). 
redactar el testament (l'abril de 1454): probablement no pas a causa del viatge al qual es referia en el seu testament, pero sf en circumstàncies relacionades amb la seva professi 6 -i devia ser bastant jove, si pensem que el 1450 encara conservava viva la seva avia materna Agnes, a qui fa una donacio molt generosa ${ }^{46}$.

\section{Conclusions}

Tots aquests testimonis demostren que, al llindar de l'edat moderna, els mercaders no havien deixat de fonamentar els seus guanys en la freqüencia dels viatges comercials per la Mediterrània ${ }^{47}$. Pero d'altra banda, es constata un augment del recurs a la delegació de les gestions encaminades a assolir aquests guanys comercials (com els viatges o els efectius intercanvis de mercaderies).

El mercader barcelon! del segle XV, en efecte, havia diversificat molt més les seves inversions, circumstància que afavoria també una major sedentaritzacio de la seva feina i, per tant, la delegacio dels afers comercials més absorbents. Entre aquestes inversions, que feien augmentar la dedicació del mercader a les tasques més organitzatives i de caire més sedentari, destaquen una major inversio en títols de renda fixa (censals $i$ violaris), una acusada tendencia a l'adquisicio de finques rústiques i el recurs als lloguers d'albergs urbans com a negoci complementari.

El comerciant tendeix a aferrar-se a un espai fix, de cara a l'adequada atencio dels seus afers comercials i financers. Estableix un centre d'operacions mercantils -la seva propia llar-, que el capacita per llançar-se a l'estranger a la recerca de millors mercats. Aixi mateix, la seguretat que li dona aquesta estabilitat li permet formar una estructura comercial suficient per poder delegar alguns aspectes de la seva feina, que li asseguri la continuïtat del negoci durant les seves absencies o el seguiment a distància d'alguna de les seves operacions comercials.

\footnotetext{
${ }^{46} I d .$, f. $34 \mathrm{v}$.

${ }^{47}$ Aquesta idea ve refennada per l'estudi de conjunt de Mario del TREPPO, Els mercaders catalans, per al que no hi ha crisi comercial -parlant en tennes estructurals- fins a la guerre civil (1462-1472), quan es produeix el veritable col.lapse i l'entrada dins un llarg període en l'atonia dels viatges inercantils per la Mediterrània.
} 
Les feines organitzatives absorbeixen cada cop més els mercaders, que han de delegar a tercers algunes de les gestions més apressants des del punt de vista comercial. L'eloqüencia dels exemples esmentats dels freqüents viatges dels mercaders i de la seva contínua mobilitat -bé a través d'enregistraments als testaments de viatges concrets per la Mediterrània, bé a través de la incertesa del lloc de la mort que traspua tota la documentacioés una prova més que els mercaders d'aquesta epoca no havien perdut tot el seu dinamisme. Tot i aixi, aquesta gran mobilitat del mercader venia de fet garantida i facilitada per una adequada direcció dels negocis, fonamentada al seu torn en una consideració molt més sedentaria de la feina mercantil: l'augment de la presencia dels estudis a les seves llars i el recurs a altres negocis de tipus no comercial -entre altres factors- aix l ho acrediten.

La convivencia a la mateixa llar mercantil dels objectes relacionats amb la vida domestico-familiar i els de la vida professional (facilment detectable a través dels inventaris d'aquest perfode) i els avanços tècnics de la feina mercantil (la possibilitat d'intercanvis a distància, la lletra de canvi, etc.) són uns altres factors que afavoreixen l'opció preferencial del mercader vers el sedentarisme. En aquest sentit, també els perills de la navegació devien haver colpit fortament les consciencies dels mercaders, cosa que els va fer recorrer progressivament a altres negocis en els quals -des d'una perspectiva física $\mathrm{i}$ des d'una perspectiva financera- els riscs no fossin tan punyents.

Tots aquests factors fan pensar que cal una renovació dels plantejaments historiografics de la Barcelona del final de l'edat mitjana, on probablement encara no s'ha posat prou emfasi en les qüestions de mentalitat, arraconades per la prevalença dels plantejaments socio-economics. En aquest sentit, no caldria buscar en els origens de la crisi posterior a la guerra civil del 1462-72 unes limitacions d'actituds dels mercaders més que no pas de poder material? L'abandonament de les activitats comercials amb més risc, que es constata a partir de la primera meitat del segle XV, és una de les manifestacions més clares d'aquest retraïment dels mercaders, manifestat en les actituds per damunt de les possessions. 


\section{RÉSUMÉ}

La forte personnalité des marchands de Barcelone à la fin du Moyen Age se doit, en grande partie, a la cohesion du groupe socio-professionnel. L'analyse du concept qu'eux même avaient de leur propre travail, peut nous aider à mieux comprendre l'identité

de ce groupe social, ainsi que son rôle au sein de la société de Barcelone vers la fin du Moyen Age. En s'appuyant sur les actes notariaux, à la manière de sources culturelles, notre article vise a approfondir quelques uns des aspects les plus représentatifs de la mentalité professionnelle des marchands qui habitaient Barcelone au XVe siècle. Parmi ces aspects, il faut remarquer une plus forte tendance à la sédentarité des travaux commerciaux et à la diversité des investissements. Il y a des tâches commerciales qui peuvent se déleguer, les dangers de la navigation augmentent -à cause des pirates et des limitations techniques-, l'organisation exige toujours plus de temps -comme nous pouvons constater par la présence des escriptoris aux foyers marchands-, et l'influence de tous ces facteurs provoque une sédentarité croissante au cas des marchands de Barcelone. L'étude de tout ce genre d'attitudes, auxquelles les historiens n'ont pas prêté trop d'attention par ce qui respecte à la Catalogne du bas Moyen Age, peut contribuer a fournir des données décisives pour comprendre dans sa totalité cette période.

\section{SUMMARY}

The market personality of Barcelona merchants by the end of the Middle Ages is greatly determined by the cohesion of this socioprofessional group. The analysis of the idea of their. own work helps to understand better the identity of this social group as well as its role in Barcelona's society during the Low Middle Ages. Resting on the notarial documents as a cultural source, this article seeks to deepen into some of the most characteristic aspects of the professional mentality of Barcelona merchants in the fifteenth century. Among these aspects, the trend towards sedentarism of the commercial work and the investment diversification stand out. The possibility of delegating some commercial tasks, the increase in navigation 
risks -due to piracy and technical boundaries- and the predominance of organizational tasks -attested by the generous presence of escriptoris in commercial places- are some of the factors contributing decisively to this progressive sedentarism of Barcelona merchants. The study of these kind of attitudes, to which historians have not paid yet much attention regarding Catalunya of the Low Middle Ages, can provide decisive data for the integral comprehension of this period. 